Terr. Atmos. Ocean. Sci., Vol. 18, No. 3, 437-457, August 2007

\title{
Model Study on the Transport and Mixing of Dust Aerosols and Pollutants During an Asian Dust Storm in March 2002
}

\author{
Xiujuan Zhao ${ }^{1,2,4}$, Zifa Wang ${ }^{2,{ }^{*}}$, Guoshun Zhuang ${ }^{1,2,3}$, and Chengming Pang ${ }^{2}$
}

(Manuscript received 23 March 2006, in final form 11 September 2006)

\begin{abstract}
The transport and mixing of dust aerosols and pollutants in East Asia during March 18 to 22, 2002 was studied using the nested air quality prediction model system (NAQPMS). Dust was primarily generated in the Gobi desert on 19 March and then swept across several areas of East Asia. The model results were verified with observations of surface weather, TSP/PM10, $\mathrm{SO}_{2}$ and lidar data. The model simulated the right timing and strength of dust events, capturing most of the variation features in dust and $\mathrm{SO}_{2}$. Numerical results showed that the dust aerosols were mainly transported in two layers and mixed with pollutants in different ways. Some of the dust kicked up in the source region was uplifted to a higher layer $(200-2000 \mathrm{~m}$ layer) and transported downwind faster than dust of the lower level. This lower-level dust was of greater concentration. The dust arriving at the upper layer began to drop and mixed well with pollutants in the atmosphere during "the first period". During "the second period", pollutants were diluted by the dust air mass that was transported along the lower layer. The remaining pollutants mixed well with dust aerosols during this period. The mixed air mass of the higher layer $(1500 \mathrm{~m})$ eventually reached the
\end{abstract}

\footnotetext{
${ }^{1}$ Center for Atmospheric Environmental Study, Department of Chemistry, Beijing Normal University, Beijing, China

${ }^{2}$ NZC/LAPC, Institute of Atmospheric Physics, Chinese Academy of Science, Beijing, China

${ }^{3}$ Center for Atmospheric Chemistry Study, Department of Environmental Science and Engineering, Fudan University, Shanghai, China

${ }^{4}$ Institute of Urban Meteorology, China Meteorological Administration, Beijing, China

* Corresponding author address: Prof. Zifa Wang, NZC/LAPC, Institute of Atmospheric Physics, Chinese Academy of Science, Beijing, China; E-mail: zifawang@mail.iap.ac.cn doi: 10.3319/TAO.2007.18.3.437(EA)
} 


\title{
Northwestern Pacific. A large amount of clouds in the upper layers poten- tially led to an increase in sulfate mass on the surface of dust particles.
}

\author{
(Key words: Dust aerosol, Pollutants, Transport, Mixing, Air quality model system)
}

\section{INTRODUCTION}

Asian dust storm events, originating from the desert regions of China and Mongolia, are frequently transported thousands of kilometers by westerly winds over the Asian continent and Pacific Ocean, and on occasions reach as far as North America (Duce et al. 1980; Uematsu et al. 2002; Cahill 2003). Mineral aerosols carried by such dust storms have a great impact on the global biogeochemical cycle and human health (Duce et al. 1983; Zhuang et al. 1992; Johnson et al. 2003). Several studies have been conducted on composition, particle size distribution, sources, and transport paths of Asian dust storms (Zhuang et al. 2001; Sun et al. 2001; Sun et al. 2002). During the spring of 2001, the ACE-Asia project, the fourth in a series of Aerosol Characterization Experiments, conducted an intensive field study to characterize aerosol properties in East Asia (Seinfeld et al. 2004). These observations were then utilized combination with a number of models to study transport and deposition of dust during dust storm events (Gong et al. 2003; Uno et al. 2003; Zhang et al. 2003). These studies have led to a better understanding of the physical and chemical characteristics and transport mechanism of Asian dust.

The rapid increase in fossil fuel burning accompanying East Asia's economic expansion has caused a dramatic increase in anthropogenic atmospheric pollutants, such as $\mathrm{SO}_{2}$, organic matter, and soot etc. As dust kicked up in the deserts of East Asia passes through high polluting regions its particles mix with pollutants through surface reactions, adsorption of gaseous species, and coagulation with other particulate matter during long-range transport. Zhang et al. (2000) using X-ray (EDX) spectrometer to study the mixture of Asian dust particles collected in Qingdao found that mineral materials could enhance the formation of particulate sulfate/ nitrate and that nitrate was predominant in the mixture on coarse mode particles. Ooki and Uematsu (2005) examined the ionic composition of size-fractionated aerosols collected along coastal Japan and the North Pacific Ocean in spring 2001 and 2002 and found that the internal mixing of nss- $\mathrm{SO}_{4}{ }^{2-}$ with mineral dust particles would be promoted by in-cloud collision. Using an atmospheric chemistry model study, Xiao et al. (1997) found that the chemical conversion of $\mathrm{SO}_{2}$ to sulfate on the surface of mineral aerosols may contribute as much as 20 $40 \%$ of total sulfate production. Observations of atmospheric aerosols with model simulation in Japan showed that it took a certain amount of time to mix the different air masses containing various types of aerosols along their transport pathways (Uematsu et al. 2002; Matsumoto et al. 2003). The mixing mechanisms and degree of mixing of dust with aerosol pollutants differed by case. More case studies are required to further understand these mixing processes.

A heavy dust storm occurred in northern China and invaded Beijing on 20 March 2002, with peak concentration of TSP reaching $10.9 \mathrm{mg} . \mathrm{m}^{-3}, 54$ times the National Air Quality Standard of China (Sun et al. 2004). Our group previously reported that this dust storm mixed with 
polluting substances along its transport pathway (Guo et al. 2004; Sun et al. 2004; Wang et al. 2005). Model analysis with lidar observation of this dust storm in Beijing revealed the source and transport path of the dust and further explained the reasons for the occurrence of such extremely high dust concentration (Sugimoto et al. 2003). This dust storm not only swept over most parts of China but also reached Korea and Japan. Using model simulation, Park and In (2003) studied dust emissions from the source areas of this dust storm. In addition, Shao et al. (2003) simulated this dust storm with an integrated modeling system and found the model could predict well the spatial pattern and temporal evolution of dust concentration. Han et al. (2004) developed a size-segregated aerosol model and coupled this with a regional air quality model to simulate the dust storms of 15 - 24 March 2002. These models captured most of the key features of dust evolution and reproduced particle size distribution along the transport pathway of the dust. However, these studies mainly focused on the storm's physical characteristics and horizontal distribution, the vertical structure of this dust storm and the mixing of dust with polluting aerosols during this period have not been reported yet. Using a chemical model combined with in situ observations, we investigate the vertical structure of this super dust storm and the mixing of dust aerosols with pollutants during the sever dust period of 18 - 22 March 2002 in East Asia.

\section{MODEL DESCRIPTION}

\subsection{The Meteorological Model}

The meteorological model used in this study is the fifth-generation mesoscale model (MM5). It provides meteorological fields including wind, temperature, humidity, surface pressure, and other surface parameters. Several main physical processes are parameterized by specific options, such as the MRF scheme for the boundary layer, Grell scheme for convective motion, and cloud-cooling scheme for radiation, etc. NCEP reanalysis data, four times a day with $1^{\circ} \times 1^{\circ}$ resolution, were used for initial and boundary conditions. Twenty-three levels were unequally distributed in the vertical from the ground to a level of $100 \mathrm{hPa}$, whereas horizontal resolution was selected as $30 \mathrm{~km}$.

\subsection{The Nested Air Quality Prediction Model System (NAQPMS)}

The Nested Air Quality Prediction Model System (NAQPMS), which handled detailed atmospheric chemistry (Wang et al. 2001, 2002), was used to reproduce the transport and changes of mineral and sulfate aerosols during the dust storm period. The model domain in this study and the potential dust emission region are shown in Fig. 1. This horizontal domain was divided into grids of $283 \times 211$ with a horizontal resolution of $30 \mathrm{~km}$. The vertical model domain consisted of 20 layers from ground level up to $15 \mathrm{~km}$ above sea level. The vertical-grid spacing increased gradually from $50 \mathrm{~m}$ at the surface to $2000 \mathrm{~m}$ at the top. This model had been successfully used to study atmospheric trace gases and particles, such as $\mathrm{SO}_{\mathrm{x}}$, dust, $\mathrm{O}_{3}$, and acid rain over East Asia (Wang et al. 2000a, 2002; Uematsu et al. 2003). 


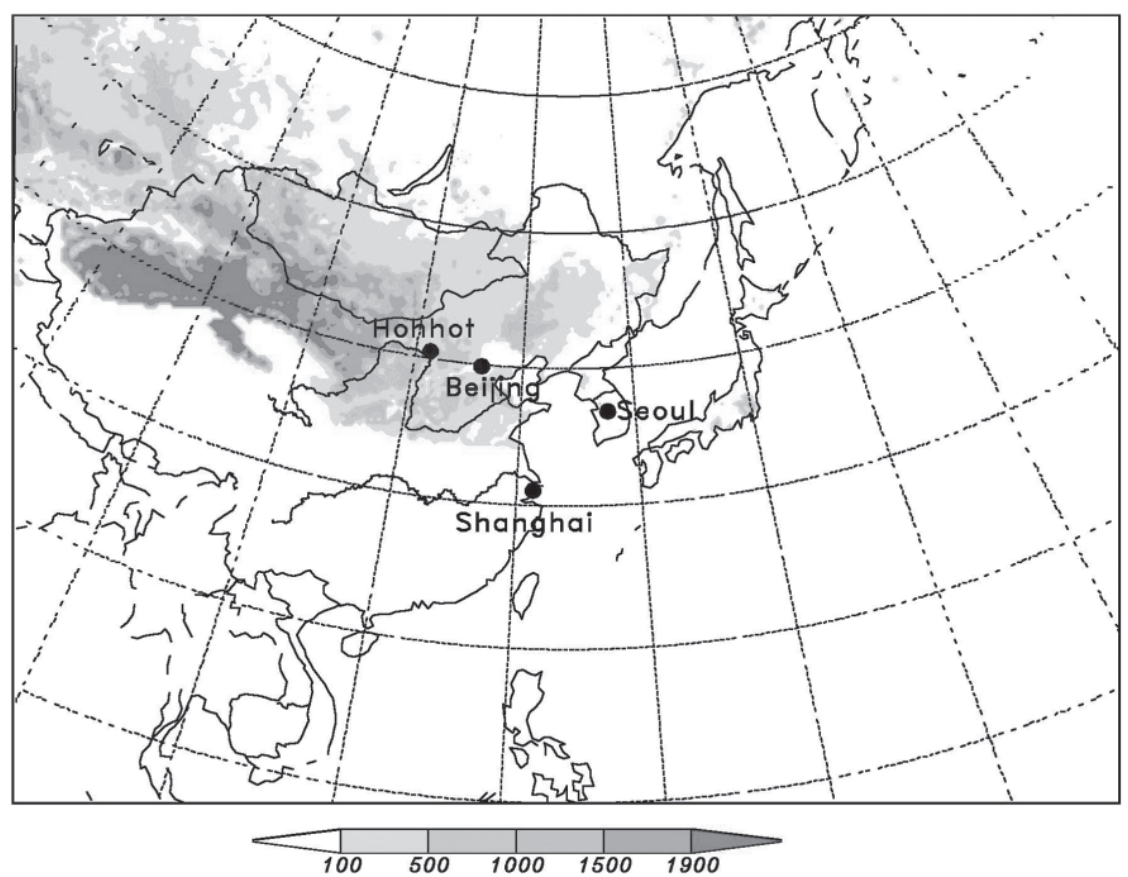

Fig. 1. Model domain and weighting factor $\left(\mathrm{C}_{\mathrm{j}}\right)$ of dust loading for different land types.

\subsection{Emissions}

A modified dust deflation module is embedded into NAQPMS. The methodology for dust emission was reported by Wang et al. (2000b). In this application, soil dust emission intensity is modified with vegetation fraction percentages and soil categories based on the approach of Wang et al. (2000b):

$$
\mathrm{Q}_{\mathrm{i}}=\mathrm{C}_{1} \times \mathrm{u} * \times\left(1-\mathrm{u}^{*}{ }_{0} / \mathrm{u}^{*}\right) \times \mathrm{W} \times \mathrm{R}_{\mathrm{i}} \times \Sigma \mathrm{C}_{\mathrm{j}} \mathrm{f}_{\mathrm{j}},
$$

Where $\mathrm{u}^{*}$ and $\mathrm{u}_{0}{ }_{0}$ are the fraction and threshold friction velocities and $\mathrm{C}_{1}$ is a constant $\left(2.9 \times 10^{-11}\right)$. $\mathrm{R}_{\mathrm{i}}$ is the fraction of dust aerosol in ith size bin to total dust emission. $C_{j}$ is the weighting factor of dust loading for $\mathrm{j}$ type of vegetation that is obtained from the U.S. Geological Survey (USGS) data with a horizontal resolution of $10 \mathrm{~min}$ (Fig. 1); $\mathrm{f}_{\mathrm{j}}$ is the vegetation fraction percentage of $\mathrm{j}$ type of vegetation in a model grid that is derived from the AVHRR data.

In this study, particles of $0.43 \sim 42 \mu \mathrm{m}$ in diameter were divided into 10 size bins in terms of the eight stages of the aerosol sampler, with three additional size bins above $11 \mu \mathrm{m}$ for larger particles. Table 1 lists the particle size ranges. The size distribution of dust emission is 
Table 1. Particle size ranges and mass size distributions of vertical dust flux for the three major desert regions of China used in this study (MSD: Mass Size Distribution).

\begin{tabular}{cccc}
\hline Bin & $\begin{array}{c}\text { Size Range in } \\
\text { Diameter }(\boldsymbol{\mu m})\end{array}$ & $\begin{array}{c}\text { Middiameter } \\
(\boldsymbol{\mu m})\end{array}$ & MSD, \% \\
\hline 1 & $0.43-0.65$ & 0.53 & 0.03 \\
2 & $0.65-1.1$ & 0.84 & 0.04 \\
3 & $1.1-2.1$ & 1.52 & 0.07 \\
4 & $2.1-3.3$ & 2.63 & 0.10 \\
5 & $3.3-4.7$ & 3.95 & 0.12 \\
6 & $4.7-7.0$ & 5.76 & 0.15 \\
7 & $7.0-11.0$ & 8.85 & 0.18 \\
8 & $11.0-17.5$ & 14.0 & 0.11 \\
9 & $17.5-27.0$ & 21.5 & 0.09 \\
10 & $27.0-42.0$ & 34.0 & 0.11 \\
\hline
\end{tabular}

an important parameter for dust simulation. In this study, total dust emission flux was apportioned to each size bin based on observations of the size distribution of soil dust in Chinese source regions within and on the edge of deserts (Gao et al. 2002; Zhang et al. 2003). The emissions of air pollutants in Asia were obtained from the East Asia inventory developed by Streets et al. (2003a, b).

\section{OBSERVATIONAL DATA}

Various observational data, including meteorological data obtained from the China Meteorological Administration (CMA), $\mathrm{SO}_{2}$ concentration at Beijing derived from the State Environmental Protection Administration (SEPA) of China, hourly PM10, and $\mathrm{SO}_{2}$ concentrations and meteorological data at Shanghai provided by Shanghai Environmental Monitor Center, were used to verify the spatial distribution, temporal variation, as well as the vertical profile of dust aerosols. The PM10 and $\mathrm{SO}_{2}$ concentrations at Shanghai were the average results collected at 18 sites in Shanghai. Aerosol sampler (Beijing Geological Instrument-Dickel Co., Ltd., model (TSP/PM $10 / \mathrm{PM}_{2.5}$ ) was employed for TSP sampling from March to April 2002 on the roof ( $\sim 40 \mathrm{~m}$ height) of the $12^{\text {th }}$ floor in the Building of Science \& Technology, Beijing Normal University. Several TSP samples with each in $2-3$ hour intervals were collected continuously 
during the dust storm period, while one TSP sample was collected in a 3-hour interval for each day on non-dust days. The samples were collected on the Whatman4l filter membrane (Whatman Company, UK) and put in polyethylene plastic bags right after sampling and preserved in a refrigerator. They were weighed after stabilizing under constant temperature $\left(20 \pm 1^{\circ} \mathrm{C}\right)$ and humidity (40 $\pm 1 \%$ ), using an analytical balance (model: Sartorius 2004MP) with a reading precision $10 \mu \mathrm{g}$. All the procedures were strictly quality-controlled to avoid any possible contamination of the samples. The lidar observation at Beijing was performed at the SinoJapan Friendship Center for Environmental Protection SJFCEP (Sugimoto et al. 2003).

\section{MODEL VALIDATION AND RESULTS}

The simulation was performed from 0800 LT 10 March to 0700 LT 23 March in this study. Spin-up time was from 0800 LT 10 March to 0700 LT 18 March. The surface weather records obtained at 3-hour intervals and other observation data were used to identify model results. In surface weather records dust events were classified into four categories: dust in suspension, blowing dust, dust storm, and severe dust storm based on horizontal visibility of less than $10 \mathrm{~km}, 1$ to $10 \mathrm{~km}, 500$ to $1000 \mathrm{~m}$ and less than $500 \mathrm{~m}$, respectively.

\subsection{Dust Emission Flux}

Figure 2 shows the spatial distribution and temporal evolution of dust emission fluxes, 10-m wind vector, as well as observed dust events. The evident dust deflation process was initiated around 0900 LT 19 March 2002 from the Gobi desert near the southwestern ChinaMongolian border. Dust flux reached a maximum of $8500 \mu \mathrm{g} \mathrm{m}^{-2} \mathrm{~s}^{-1}$ at $1400 \mathrm{LT} 19$ March (Fig. 2a) and then the emission intensity decreased. The soil dust over southeastern Mongolia and the north of Shannxi and Shanxi provinces of China was uplifted on 20 March (Fig. 2b). On 21 March, the dust mainly deflated over semiarid areas, east and southwest of Inner-Mongolia (Fig. 2c), north of Beijing and Shanxi provience, as well as the eastern part of Taklimakan desert. In general, the modeled dust deflation agreed well with the dust-rise in spatial distribution and temporal evolution reported. Major dust generation occurred in the Gobi desert and the semiarid areas of Inner-Mongolia, which was much higher than that in Taklimakan desert.

Dust emission of this study showed general agreement with previous studies of this dust storm. Location and timing of dust deflation were quite similar to Shao et al. (2003) and Han et al. (2004). However, there were relatively large differences in the intensity of dust emission. The maximums of dust emission predicted by Park and In (2003) and Han et al. (2004) were 3500 and $12000 \mu \mathrm{g} \mathrm{m}^{-2} \mathrm{~s}^{-1}$, respectively, whereas the highest dust emission in Shao et al. (2003) was $5000 \mu \mathrm{g} \mathrm{m}^{-2} \mathrm{~s}^{-1}$. The maximum of this study, $8500 \mu \mathrm{g} \mathrm{m}^{-2} \mathrm{~s}^{-1}$, was between Park and In (2003) and Shao et al. (2003). A comparison of spatial distribution and temporal evolution of dust emission among these studies gives our modeled dust emissions as being mostly consistent with Shao et al. (2003) and Han et al. (2004). The differences exiting in the intensity of dust emission should be mainly due to the different emission mechanisms used in these studies. On the whole, dust emission simulated by our model showed good agreement with the reported dust-rise record, and was generally consistent with previous studies. 

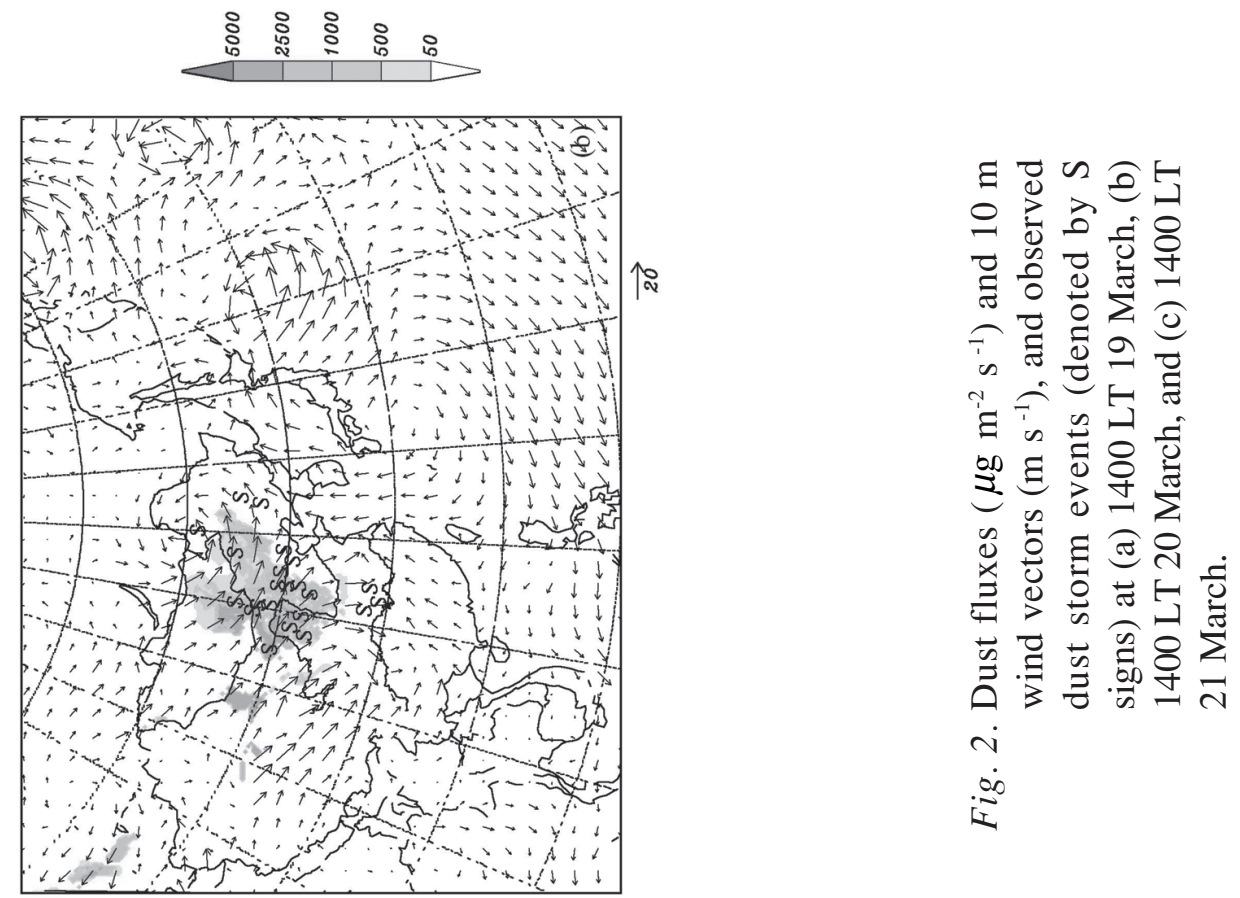

$\hat{e}$
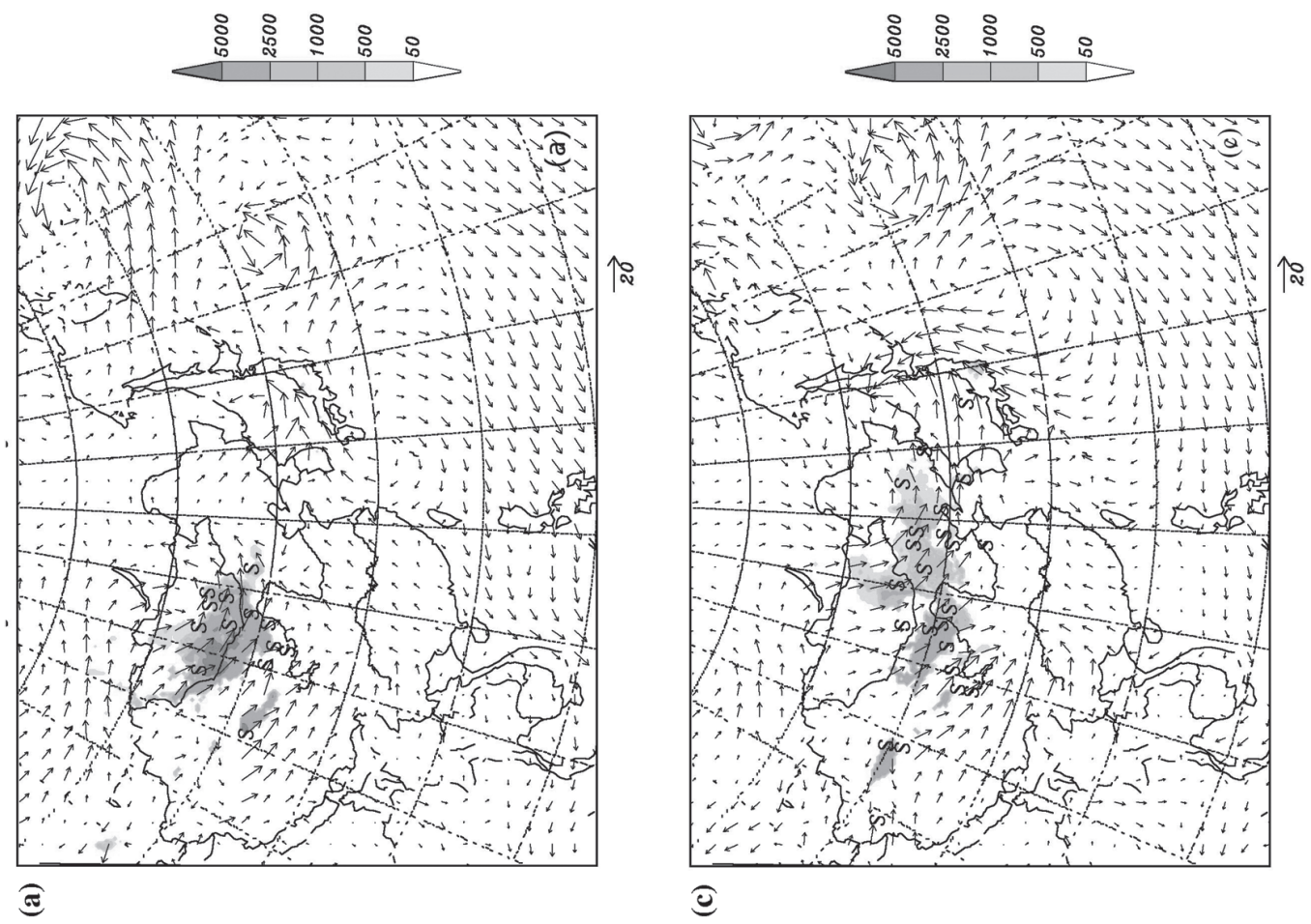


\subsection{Spatial Distributions of Dust Aerosols}

Distribution of simulated total concentration of dust aerosols near the surface level and observed dust events derived from meteorological networks are shown in Fig. 3. The spatial pattern and temporal variation of dust concentration in the model agreed quite well with the observed dust event. The dust storm originating in southern Mongolia and west Inner Mongolia was around $20000 \mu \mathrm{g} \mathrm{m}^{-3}$ on March 19 (Fig. 3a). The main body of the dust storm moved eastward and southeastward in a widespread manner and its border reached Beijing at $0800 \mathrm{LT}$ on March 20. Then the dust storm invaded Beijing and was refilled by dust emissions over the southeastern China-Mongolia border on March 20 (Fig. 3b). The dust air mass extended over Northeast China to central China. Thereafter, the dust air mass moved northeastward and was
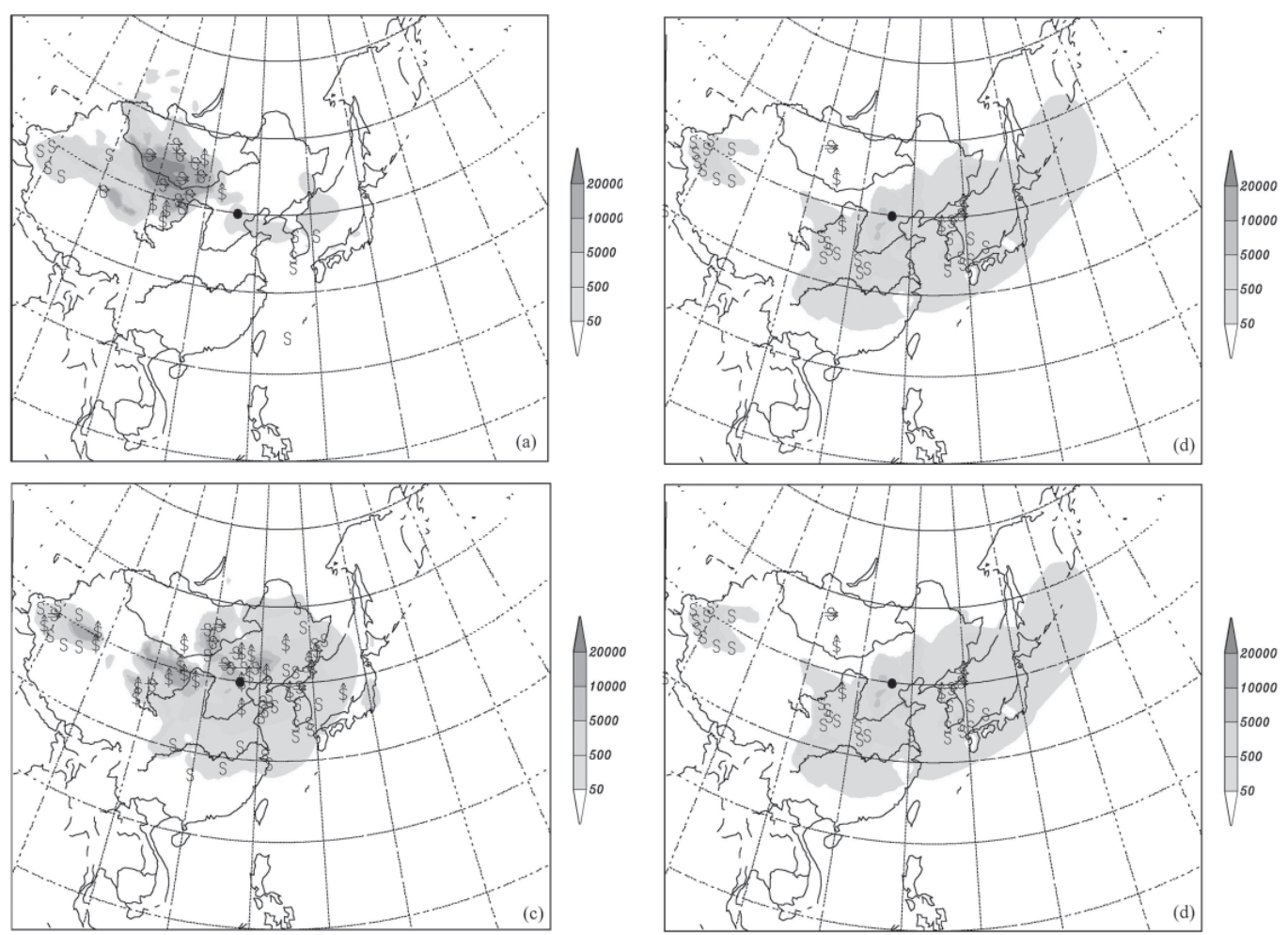

Fig. 3. Simulated total soil dust concentration $\left(\mu \mathrm{g} \mathrm{m}^{-3}\right)$ at surface and dust events at: (a) 1400 LT 19 March, (b) 1400 LT 20 March, (c) 1400 LT 21 March, and (d) 1400 LT 22 March. Dust in suspension is denoted by S, blowing dust denoted by $\mathrm{S}$ superposed by a vertical arrow, and various intensities of dust storms are denoted by $\mathrm{S}$ superposed by a single horizontal arrow and double ones. The solid circle in the figure indicates Beijing. 
refilled again in the north of Beijing and in western Inner Mongolia, and moved to Shanghai and the Korean peninsula (Fig. 3c). On March 22, the dust air mass moved east-northeastward and reached northern Japan (Fig. 3d). The concentration of dust aerosols became very low with the abatement of the dust storm. The time evolutionary pattern of the total surface concentration of dust aerosols agreed well with the recorded dust events.

\subsection{Temporal Variation of Dust and $\mathrm{SO}_{2}$ Concentrations at Beijing and Shanghai}

Figure 4a shows a time series of the simulated dust concentrations and the observed TSP concentrations in Beijing. The time evolution of the dust storm simulated by the model agreed well with observations. The highest dust peak around noon of March 20 was reproduced well, though simulated dust concentration was overestimated in the afternoon of March 20. Two small dust peaks observed around 2000 LT on March 21 and 22 were simulated well by the

(a)

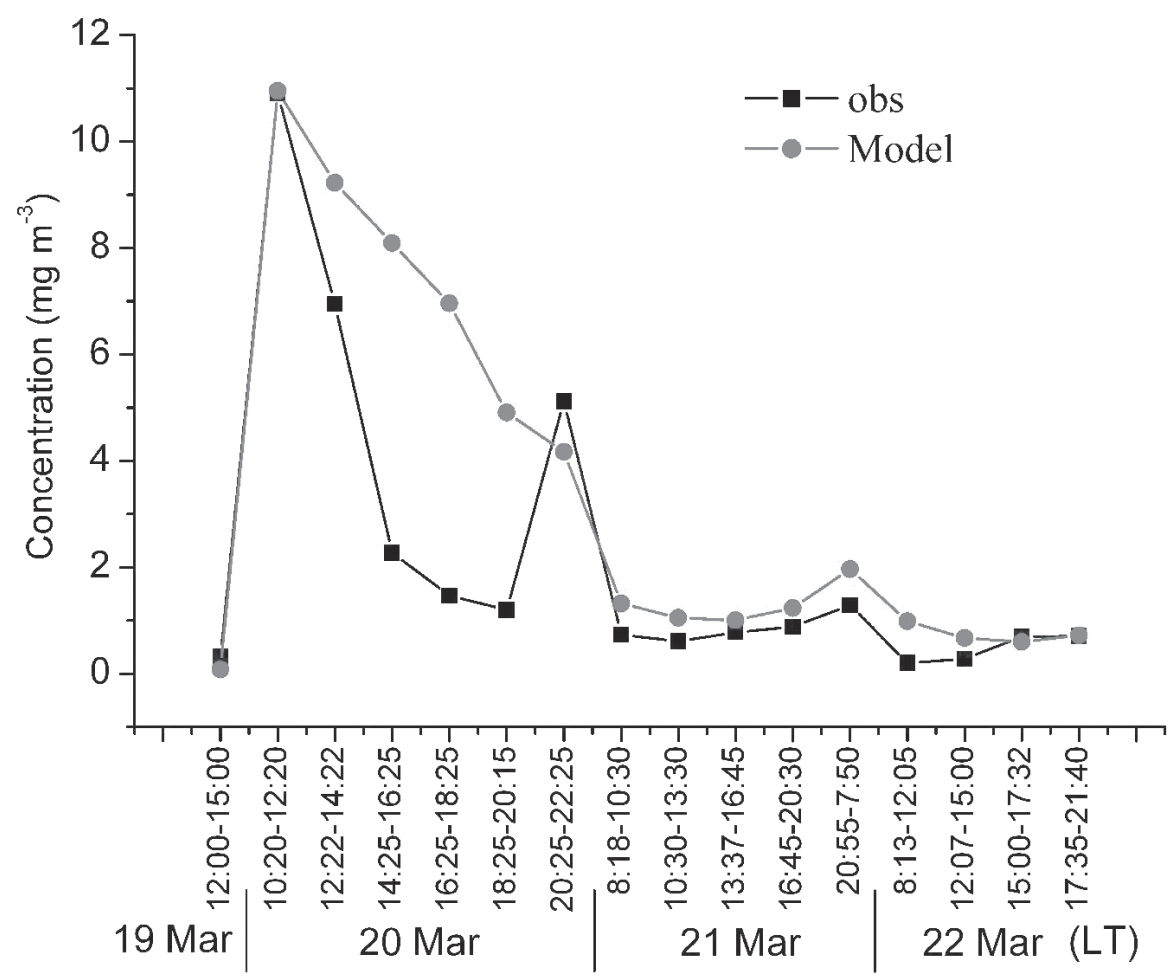

Fig. 4. Time series of simulated dust concentration and observed concentration of: (a) TSP at Beijing for the period of 19 - 22 March 2002 (simulated concentration was averaged for the corresponding period of observation); (b) hourly PM10 at Shanghai for the period 18 - 22 March. 
(b)

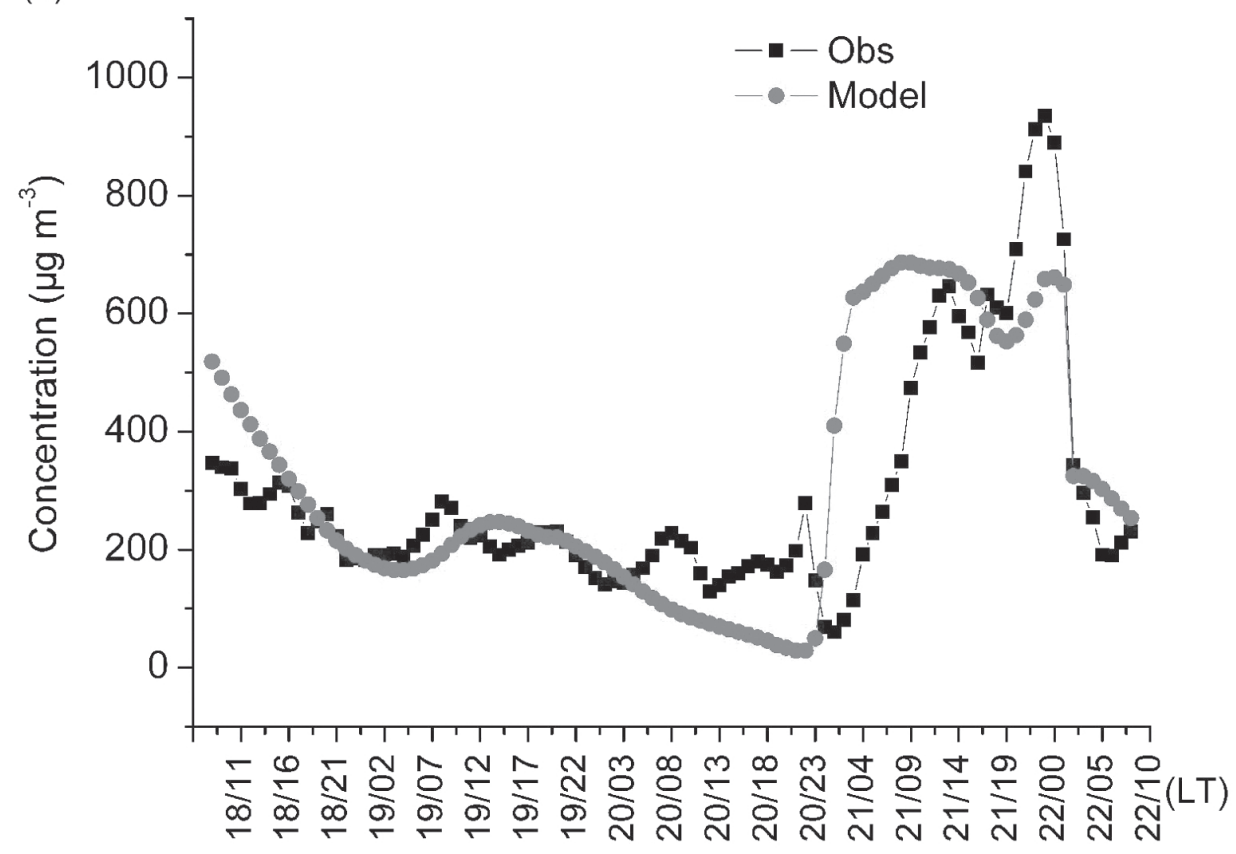

Fig. 4. (Continued)

model with slightly different times of occurrences on March 21. However, the second TSP peak observed in the night of March 20 was missed in the modeled results; it was covered up by the overestimated dust in the afternoon. In Shanghai, the model simulated well the observed PM10 concentration (Fig. 4b). Two peak values of observed PM10 concentration were well simulated by the modeled PM10 concentration with slightly different times of occurrences, but the concentration of the second peak seemed to be underestimated. In general, the model reproduced well the concentration of particulate matter during this dust storm.

The vertical structure of the dust concentration at Beijing is shown in Figs. 5 and 6. The dust particles firstly arrived at Beijing at the high layer (about $1800 \mathrm{~m}$ above surface) at $0500 \mathrm{LT}$ on March 20, which was observed by lidar (Fig. 6a). Then the dust at the lower layer, which was restricted below $1000 \mathrm{~m}$ with a maximum at $500 \mathrm{~m}$ appeared at $0800 \mathrm{LT}$, the dust transported along the surface reached Beijing after 1000 LT. The modeled dust concentration showed a similar feature to that of the dust extinction coefficient, while the model showed a lower dust layer at $0500 \mathrm{LT}$ on March 20 (Fig. 6). These results indicate that some dust aerosols were transported to Beijing in the higher layer $(500-1000 \mathrm{~m})$ before that transported at the lower level. The lower level dust was being transported more slowly but was of a higher concentration. The model captured this main feature of the vertical structure of dust concentration at Beijing. 
At Seoul the dust concentration showed similar variation to that at Beijing (Fig. 8). The dust reached the upper layer earlier with its highest concentration appearing at between $200-1500 \mathrm{~m}$ on March 21; it then settled progressively toward the surface on March 22. The dust at Seoul from 19 to 20 March was the production of another dust storm generated in the sand lands in the northeast of China on March 18 and transported to Seoul on March 19 (Fig. 3a). The modeled results agree well with previous work (Park and In 2003). These results indicate that the dust was mainly transported by two layers. Dust was kicked up in the source region by a low-pressure system and uplifted to the higher layer (200 - $2000 \mathrm{~m}$ layer), and transported downwind at a faster rate to dust accumulating in the lower layer. Lower-layer dust was transported in much greater concentration, which was the main body of the dust storm. The higher layer of dust was caused by strong horizontal advection. The profile of wind speed at the beginning of the dust event at different locations indicates that there was a layer of higher wind speed at 200 to $2000 \mathrm{~m}$ above the surface (Fig. 7). The highest wind speed reached was $15 \mathrm{~m} \mathrm{~s}^{-1}$ in this layer. Such a strong wind could lead to the strong horizontal advection that carried the higher-layer dust downwind before it mixed with air masses from ground level.

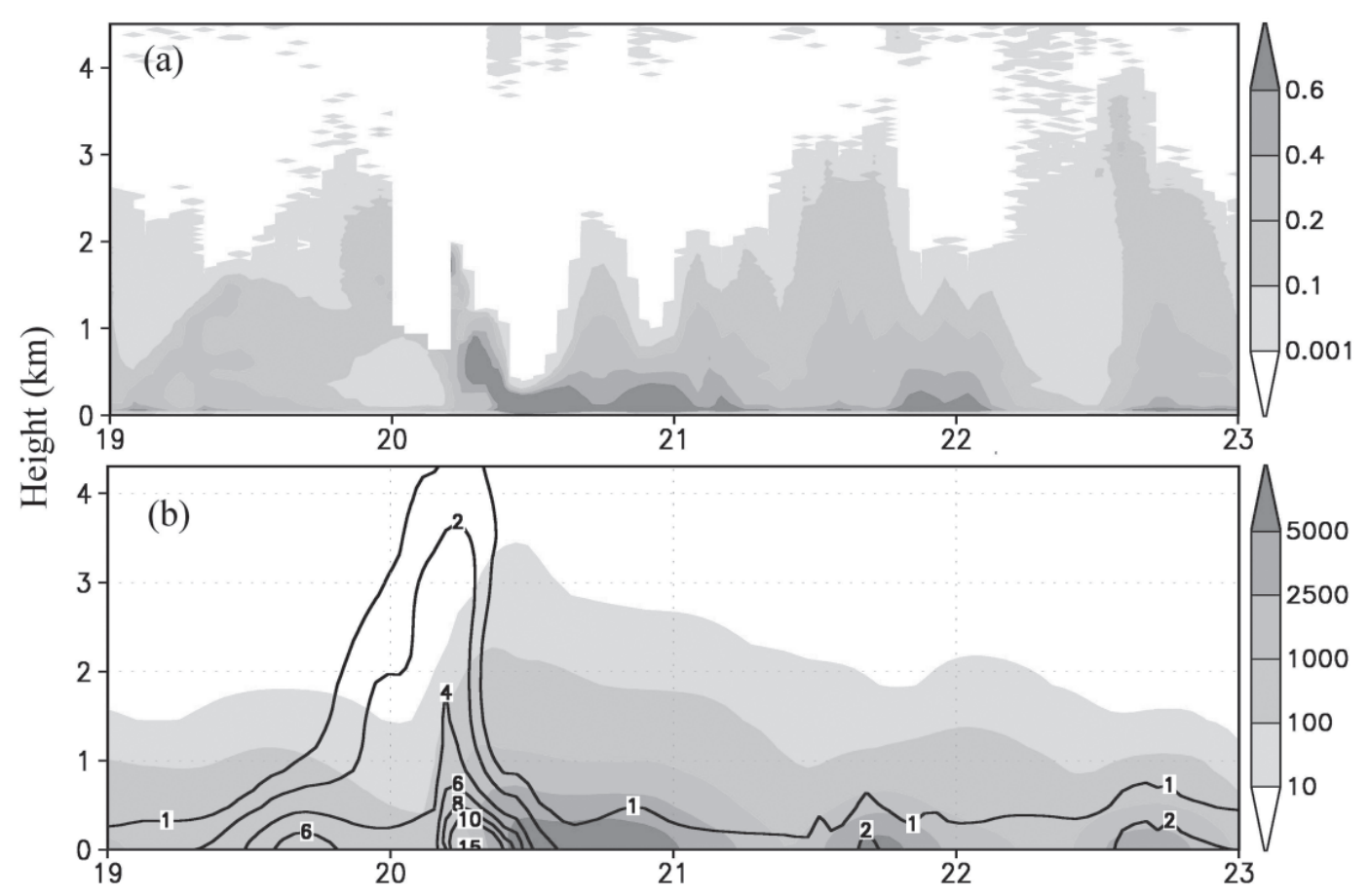

Fig. 5. Time-height cross sections of: (a) the dust aerosol extinction coefficient $\left(\mathrm{km}^{-1}\right)$ from Lidar observation at Beijing; and (b) modeled dust concentration (shaded $\mu \mathrm{g} \mathrm{m}^{-3}$ ) with the sulfate concentration (contour line $\mu \mathrm{g} \mathrm{m}^{-3}$ ) at Beijing from 0000 LT 19 to 0000 LT 23 March 2002. 

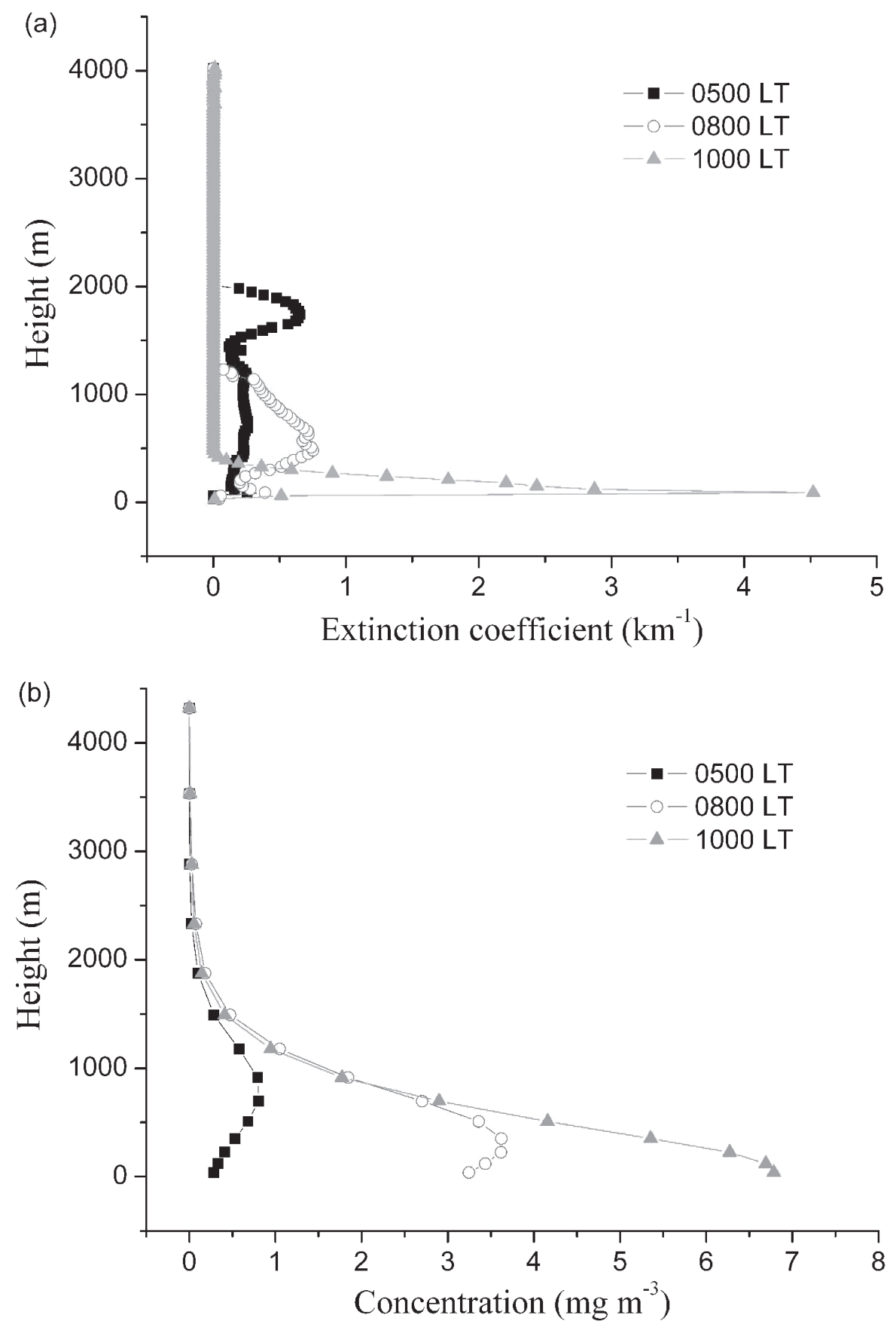

Fig. 6. (a) Lidar-observed extinction coefficient of dust $\left(\mathrm{km}^{-1}\right)$; and (b) NAQPMS modeled dust concentration $\left(\mathrm{mg} \mathrm{m}^{-3}\right)$ at Beijing at marked time of 20 March. 


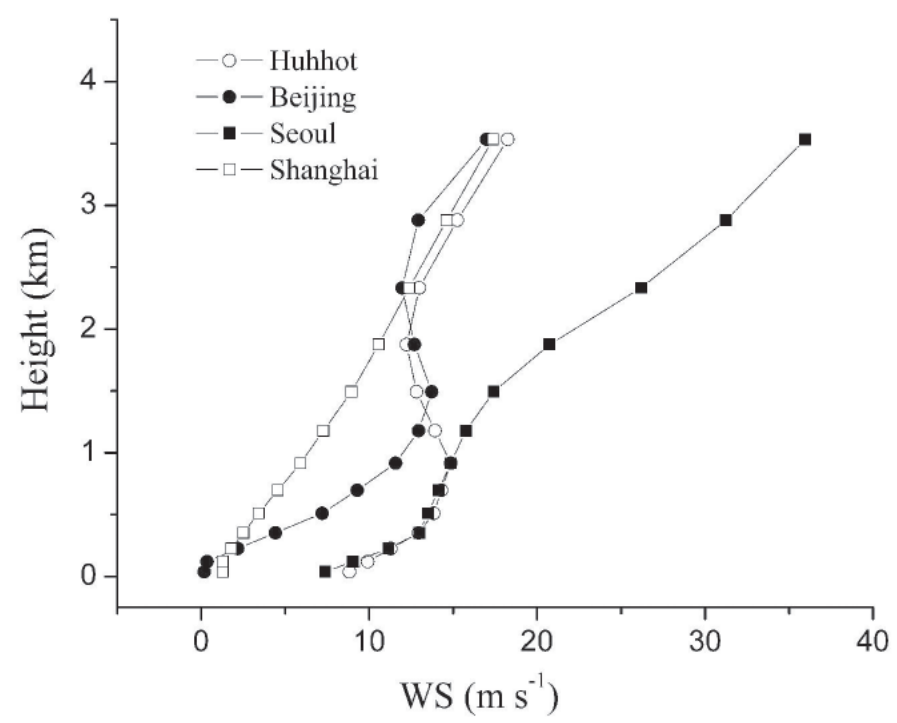

Fig. 7. Modeled vertical profile of wind speed at the beginning of the dust event at different locations (Huhhot: 2200 LT on March 19; Beijing: 0800 LT on March 20; Seoul: 1100 LT on March 21; Shanghai: 1100 LT on March 21).

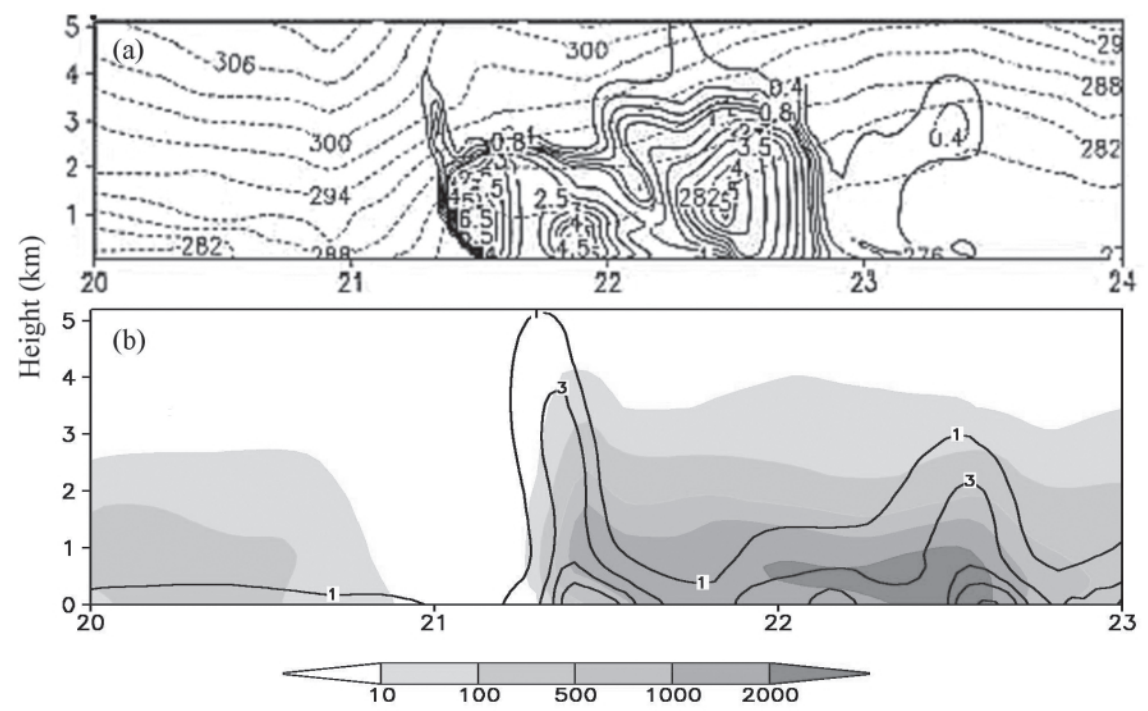

Fig. 8. Time-height cross sections of: (a) dust concentration (solid line, $1000 \mu \mathrm{g} \mathrm{m}^{-3}$ ) with the potential temperature (dashed line, K) at Seoul modeled by Park and In (2003) from 0000 LT 20 to 0000 LT 24 March; (b) dust concentration (shaded $\mu \mathrm{g} \mathrm{m}^{-3}$ ) with the sulfate concentration (contour line $\mu \mathrm{g} \mathrm{m}^{-3}$ ) at Seoul from 0000 LT 19 to 2300 LT 22 March 2002 modeled with NAQPMS. 
The time series of simulated and observed hourly $\mathrm{SO}_{2}$ concentration at Shanghai is shown in Fig. 9a. Modeled $\mathrm{SO}_{2}$ generally agreed with observations with a correlation coefficient 0.72 during March 18 - 20. However, there were some discrepancies between the simulation and observations for uncertainties in the emission inventory and the smooth effect of the model. The $\mathrm{SO}_{2}$ concentration increased from $0400 \mathrm{LT}$ and reached a peak value on $1200 \mathrm{LT}$ on March 21, which was similar to that of PM10 during this period (Fig. 4b). The wind speed was very low (below $2.2 \mathrm{~m} \mathrm{~s}^{-1}$ ) and the wind was mainly south (around 180 degrees) during the same period (not shown here). This indicates that $\mathrm{SO}_{2}$ was mostly produced by local emission and some was transported from the southern region of China. The increase of $\mathrm{SO}_{2}$ during this same period was due to the cold front accompanying the dust event. Weather processes of a cold front and a quasi-static front both can lead to a peak in $\mathrm{SO}_{2}$ for Shanghai (Zou et al. 1991). Dropping dust from the higher layer resulted in a sharp increase in PM10 for Shanghai at the beginning of dust event. The dropped dust particles mixed well with anthropogenic pollutants during this period. This period was defined as "the first period" of mixing. After 1300 LT maximum dust concentration arrived at the surface level with a northerly wind (around 90 degrees) and the concentration of $\mathrm{SO}_{2}$ decreased rapidly. This indicated that the anthropogenic pollutants were diluted by the dust air mass and some were blown out of Shanghai by the northerly wind. This process could also be found at Seoul, where sulfate concentration under $1000 \mathrm{~m}$ still increased after the dust had arrived at the high layer, then decreased rapidly when the lower layer of concentrated dust subsided at the surface (Fig. 8b). The observed daily average $\mathrm{SO}_{2}$ concentration at Beijing converted from the Air Pollution Index (API) through a standard formula prescribed by SEPA (based on spatial and daily average of observational data at a number of monitoring sites in Beijing) was used to validate the simulated results (Fig. 9b). The model could successfully simulate the variation of $\mathrm{SO}_{2}$ concentration after the dust storm arrived. However, the magnitude of $\mathrm{SO}_{2}$ concentrations at both Beijing and Shanghai were generally lower than observations. This was mainly due to the emission inventory of the anthropogenic pollutant used in this study. As the emission inventory was developed on the base of data before 2000, the new emissions after 2000 were not included in this inventory, which caused the underestimation of $\mathrm{SO}_{2}$ at these big cities. Furthermore, the model result in each grid was an average over $30 \times 30 \mathrm{~km}$, which could smooth out the peak values in the grid.

\subsection{The Mixing of Dust with Pollution Aerosols}

In this study, sulfate produced by secondary reaction represents anthropogenic pollutants. The distribution of dust and sulfate aerosols at the surface level is shown in Fig. 10. On March 19 , the greatest sulfate concentration was shown to be in the eastern coastal area of China, while the center of the dust storm was over Mongolia. The air mass containing mineral dust was separated from that containing the pollutant (sulfate). The dust particles moved southeasterly after the cold front system, and the polluted sulfate air mass was pushed to the southeast by a strong northwesterly wind, and was carried to the northeast of Japan and Japanese Sea by the cyclone of March 20. The gradient of the sulfate concentration became steep along the dust front at $1400 \mathrm{LT}$ on March 20 (Fig. 10b). The sulfate concentration below $1000 \mathrm{~m}$ decreased sharply after the dust storm arrived in Beijing (Fig. 5a). The air mass containing dust mixed 

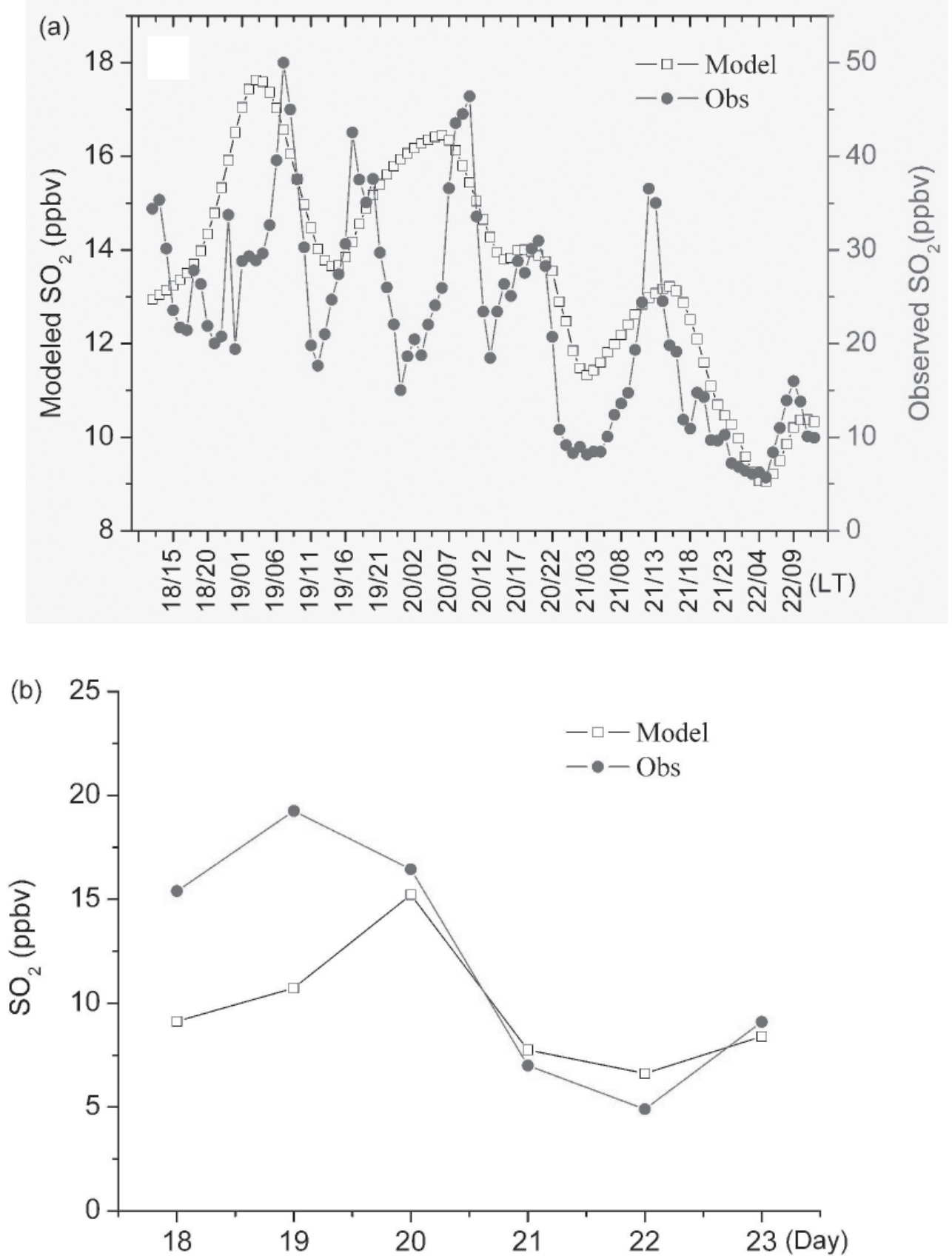

Fig. 9. Time series of simulated and observed: (a) hourly $\mathrm{SO}_{2}$ concentration at Shanghai for the period 18 - 22 March 2002; (b) daily average of $\mathrm{SO}_{2}$ concentration at Beijing for the period of 19 - 22 March (simulated concentration was averaged for the corresponding period of observation). 

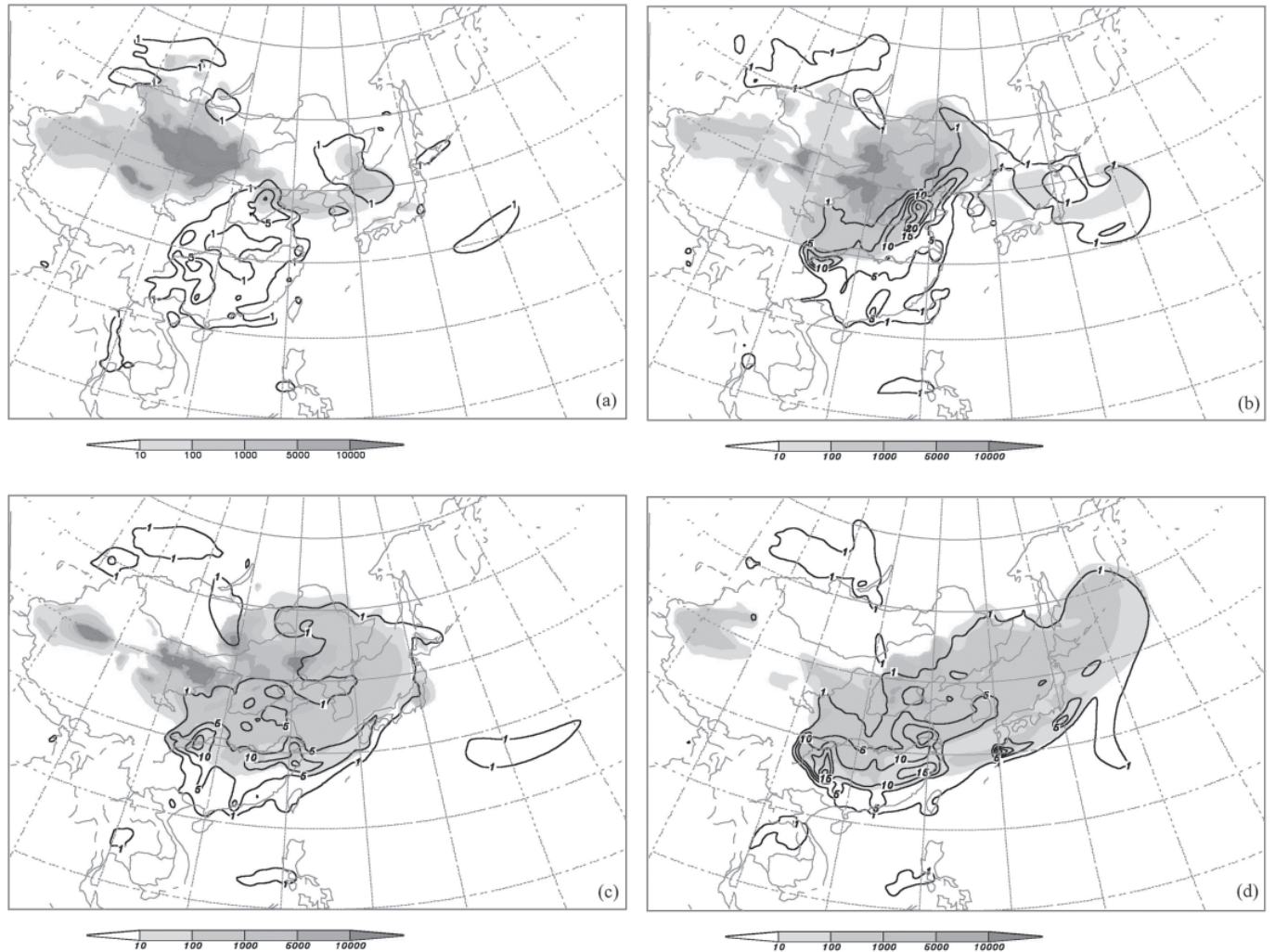

Fig. 10. Modeled dust (shaded: $\mu \mathrm{g} \mathrm{m}^{-3}$ ) and sulfate (contour lines for 1, 5, 10, 15, and $20 \mu \mathrm{g} \mathrm{m}^{-3}$ ) concentration at surface at: (a) $1400 \mathrm{LT} 19$ March, (b) 1400 LT 20 March, (c) 1400 LT 21 March, and (d) 1400 LT 22 March.

with the air mass containing sulfate to some extent at the edges of both air masses. On March 21, the dust spread widely with the abatement of the low-pressure system and had reached Shanghai and Korea (Fig. 10c). In these downwind areas, dust first arrived at the upper layer and then settled to the lower layer. The dust particles dropping from the higher layer mixed well with pollutants in the atmosphere during "the first period" as discussed in section 4.3. After the dust plume arrived along the surface, the anthropogenic pollutants were diluted by the dust air mass. The weak gradient of sulfate indicates that the pollutant air mass mixed well with the dust air mass over downwind areas. This period was defined as "the second period" of mixing. On March 22, the dust aerosols were transported to Japan and the Northwestern Pacific and mixed well with the sulfate aerosols over eastern and southern China, Korea, the southern reaches of Japan, and the interconnecting seas. Figure 11 shows early arrival dust and sulfate mixing well at the upper layer over eastern China, the Yellow Sea, and Japan before reaching as far away as the Northwestern Pacific. During this dust storm period there were a large 

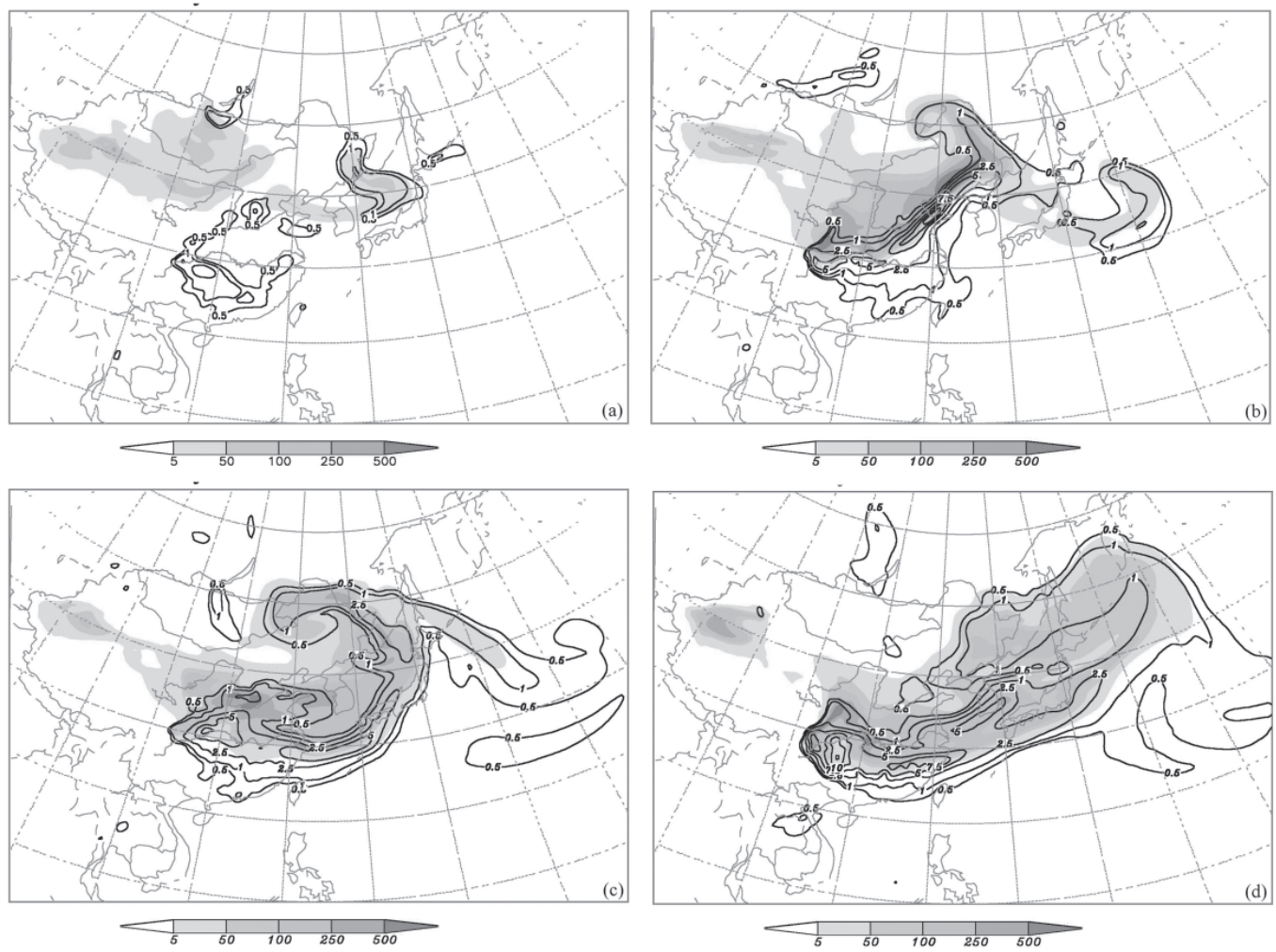

Fig. 11. Modeled dust (shaded: $\mu \mathrm{g} \mathrm{m}^{-3}$ ) and sulfate (contour lines for $0.5,1,2.5$, 5, 7.5, and $10 \mu \mathrm{g} \mathrm{m}^{-3}$ ) concentration at $1500 \mathrm{~m}$ at: (a) $1400 \mathrm{LT} 19$ March, (b) 1400 LT 20 March, (c) 1400 LT 21 March, and (d) 1400 LT 22 March.

amount of clouds in the upper layers (the height of lower cloud ranged from 1000 to $2500 \mathrm{~m}$ and the cloudiness of lower cloud was $80 \%$ at Beijing). When the dust particles passed through clouds, the liquid phase oxidation of $\mathrm{SO}_{2}$ and the coagulation of drops containing soluble sulfate could have potentially led to increased sulfate mass on the surface of dust particles (Wurzler et al. 2000). These dust particles coated with soluble sulfate would become efficient cloud condensation nuclei $(\mathrm{CCN})$ and modify the amount and acidity of precipitation.

\section{CONCLUSIONS}

The nested air quality prediction model system (NAQPMS) was used to analyze the transport and mixing of dust and pollution aerosols during a super dust storm in East Asia from 18 to 22 March 2002. Various observational data were used to evaluate the model performance. The simulated emission flux and spatio-temporal distribution of dust agreed well with the 
surface weather observations. The model reasonably reproduced the vertical structure and time series of dust aerosols and $\mathrm{SO}_{2}$.

The results from the model study indicated that dust was mainly transported at two layers during the dust storm period. Some dust was kicked up in the source region and uplifted to an upper layer (200 - $2000 \mathrm{~m})$, and transported to downwind faster. Other dust was transported more slowly at a lower level with much greater concentration. The time series of $\mathrm{SO}_{2}$ and the spatio-temporal distributions of dust and sulfate aerosols revealed that there were two periods of mixing between the air masses containing the dust aerosols and pollutants. The dust arriving at the upper layer dropped from this higher layer and mixed well with pollutants in the atmosphere during "the first period". The pollutants were then diluted by the dust air mass that was transported along the lower layer during "the second period". The remaining pollutants mixed well with the dust aerosols during this period. Eventually, the mixed air mass at the upper layer $(1500 \mathrm{~m})$ reached the Northwestern Pacific. The large amount of upper-layer cloud could have led to increased sulfate mass on the surface of dust particles. Further studies of the physical mixing processes and the chemical reactions of the dust aerosol with the pollutants are needed.

Acknowledgements This work was supported by the 100-talent project of CAS on Dust Transport and its impact on the climate and environment and NSFC Project (40305018), and also by the National Natural Science Foundation of China (Grant Nos. 30230310, 20477004, and 40575062), and Beijing Natural Science Foundation (Grant No. 8041003). We would like to thank Aohan Tang, Wenjie Zhang, and Yele, Sun from the CAES of Beijing Normal University for collecting the TSP samples. We are appreciative of Dr. N. Sugimoto for providing lidar observation data, and Shanghai Environmental Monitor Center providing observation PM10 data, $\mathrm{SO}_{2}$ and meteorological data at Shanghai.

\section{REFERENCES}

Cahill, C. F., 2003: Asian aerosol transport to Alaska during ACE-Asia. J. Geophys. Res., 108, 8664, doi: 10.1029/2002JD003271.

Duce, R. A., C. K. Unni, B. J. Ray, J. M. Prospero, and J. T. Merrill, 1980: Long-range atmospheric transport of soil dust from Asia to the tropical North Pacific: Temporal variability. Science, 209, 1522-1524.

Duce, R. A., R. Arimoto, B. J. Ray, C. K. Unni, and P. J. Harder, 1983: Atmospheric trace elements at Enewetak Atoll: 1. Concentrations, sources, and temporal variability. $J$. Geophys. Res., 88, 5321-5342.

Gao, W., W. Wei, and M. Liu, 2002: Analysis on the regional characteristics of sand-dust aerosol over Tarim Basin. Arid Land Geography, 25, 165-169.

Gong, S. L., X. Y. Zhang, T. L. Zhao, I. G. Mckendry, D. A. Jaffe, and N. M. Lu, 2003: Characterization of soil dust aerosol in China and its transport and distribution during 2001 ACE-Asia: 2. Model simulation and validation. J. Geophys. Res., 108, 4262, doi: 
10.1029/2002JD002633.

Guo, J., K. A. Rahn, and G. Zhuang, 2004: A mechanism for the increase of pollution elements in dust storms in Beijing. Atmos. Environ., 38, 855-862.

Han, Z., H. Ueda, K. Matsuda, R. Zhang, K. Arao, Y. Kanai, and H. Hasome, 2004: Model study on particle size segregation and deposition during Asian dust events in March 2002. J. Geophys. Res., 109, D19205, doi: 10.1029/2004JD004920.

Johnson, K. S., V. A. Elrod, S. E. Fitzwater, J. N. Plant, F. P. Chavez, S. J. Tanner, R. M. Gordon, D. L. Westphal, K. D. Perry, J. Wu, and D. M. Karl, 2003: Surface oceanlower atmosphere interactions in the Northeast Pacific Ocean Gyre: Aerosols, iron, and the ecosystem response. Global Biogeochem. Cycles, 17, 32-1-11.

Matsumoto, K., Y. Uyama, T. Hayano, H. Tanimoto, I. Uno, and M. Uematsu, 2003: Chemical properties and outflow patterns of anthropogenic and dust particles on Rishiri Island during the Asian Pacific Regional Aerosol Characterization Experiment (ACEAsia). J. Geophys. Res., 108, 8666, doi: 10.1029/2003JD003426.

Ooki, A., and S. Uematsu, 2005: Chemical interactions between mineral dust particles and acid gases during Asian dust events. J. Geophys. Res., 110, D03201, doi: 10.1029/ 2004JD004737.

Park, S., and H. In, 2003: Parameterization of dust emission for the simulation of the yellow sand (Asian dust) event observed in March 2002 in Korea. J. Geophys. Res., 108, 4618, doi: 10.1029/2003JD003484.

Seinfeld, J. H., G. R. Carmichael, R. Arimoto, W. C. Conant, F. J. Brechtel, T. S. Bates, T. A. Cahill, A. Clarke, S. J. Doherty, P. J. Flatau, B. J. Huebert, J. Kim, K. M. Markowicz, P. K. Quinn, L. M. Russell, P. B. Russell, A. Shimizu, Y. Shinozuka, C. H. Song, Y. Tang, I. Uno, A. M. Vogelmann, R. J. Weber, J. Woo, and X. Y. Zhang, 2004: ACEASIA: Regional climatic and atmospheric chemical effects of Asian dust and pollution. Bull. Amer. Meteor. Soc., 85, 367-380.

Shao, Y., Y. Yang, J. Wang, Z. Song, L. M. Leslie, C. Dong, Z. Zhang, Z. Lin, Y. Kanai, S. Yabuki, and Y. Chun, 2003: Northeast Asian dust storms: Real-time numerical prediction and validation. J. Geophys. Res., 108, 4691, doi: 10.1029/2003JD003667.

Streets, D. G., K. F. Yarber, J. H. Woo, and G. R. Carmichael, 2003: Biomass burning in Asia: Annual and seasonal estimates and atmospheric emissions. Global Biogeochem. Cycles, 17, doi: 10.1029/2003GB002040.

Streets, D. G., T. C. Bond., G. R. Carmichael, S. D. Fernandes, Q. Fu, D. He, Z. Klimont, S. M. Nelson, N. Y. Tsai, M. Q. Wang, J. H. Woo, and K. F. Yarber, 2003: An inventory of gaseous and primary aerosol emissions in Asia in the year 2000. J. Geophys. Res., 108, 8809, doi: 10.1029/2002JD003093.

Sugimoto, N., I. Uno, M. Nishikawa, A. Shimizu, I. Matsui, X. Dong, Y. Chen, and H. Quan, 2003: Record heavy Asian dust in Beijing in 2002: Observations and model analysis of recent events. Geophys. Res. Lett., 30, 1640, doi: 10.1029/2002GL016349.

Sun, J., M. Zhang, and T. Liu, 2001: Spatial and temporal characteristics of dust storms in China and its surrounding regions, 1960-1999: Relations to source area and climate. $J$. Geophys. Res., 106, 10325-10333.

Sun, J., T. Liu, and Z. Lei, 2002: Sources of heavy dust fall in Beijing, China on April 16, 1998. Geophys. Res. Lett., 27, 895-901. 
Sun, Y., G. Zhuang, H. Yuan, X. Zhang, and J. Guo, 2004: Characteristics and sources of 2002 super dust storm in Beijing. Chinese Sci. Bull., 49, 698-705.

Uematsu, M., A. Yoshikawa, H. Muraki, K. Arao, and I. Uno, 2002: Transport of mineral and anthropogenic aerosols during a Kosa even over East Asia. J. Geophys. Res., 107, 4509, doi: 10.1029/2001JD000333.

Uematsu, M., Z. Wang, and I. Uno, 2003: Atmospheric input of mineral dust to the western North Pacific region based on direct measurements and a regional chemical transport model. Geophys. Res. Lett., 30, 1342, doi: 10.1029/2002GL016645.

Uno, I., G. R. Carmichael, D. G. Streets, Y. Tang, J. J. Yienger, S. Satake, Z. Wang, J. H. Woo, S. Guttikunda, M. Uematsu, K. Matsumoto, H. Tanimoto, K. Yoshioka, and T. Iida, 2003: Regional chemical weather forecasting system CFORS: Model descriptions and analysis of surface observations at Japanese island stations during the ACE-Asia experiment. J. Geophys. Res., 108, 8668, doi: 10.1029/2002JD002845.

Wang, Y., G. Zhuang, Y. Sun, and Z. An, 2005: Water-soluble part of the aerosol in the dust storm season - Evidence of the mixing between mineral and pollution aerosols. Atmos. Environ., 39, 7020-7029.

Wang, Z., W. Sha, and H. Ueda, 2000a: Numerical modeling of pollutant transport and chemistry during a high-ozone event in northern Taiwan. Tellus B, 52, 1189-1205.

Wang, Z., H. Ueda, and M. Huang, 2000b: A deflation module for use in modeling long-range transport of yellow sand over East Asia. J. Geophys. Res., 105, 26947-26959.

Wang, Z., T. Maeda, M. Hayashi, L. F. Hshiao, and K. Y. Liu, 2001: A nested air quality prediction modeling system for urban and regional scales: Application for high-ozone episode in Taiwan. Water, Air, and Soil Pollution, 130, 391-396.

Wang, Z., H. Akimoto, and I. Uno, 2002: Neutralization of soil aerosol and its impact on the distribution of acid rain over east Asia: Observations and model results. J. Geophys. Res., 107, 4389, doi: 10.1029/2001JD001040.

Wurzler, S., T. G. Reisin, and Z. Levin, 2000: Modification of mineral dust particles by cloud processing and subsequent effects on drop size distributions. J. Geophys. Res., 105, 4501-4512.

Xiao, H., G. R. Carmichael, J. Durchenwald, 1997: Long-range transport of $\mathrm{SO}_{\mathrm{x}}$ and dust in East Asia during the PEM B Experiment. J. Geophys. Res., 102, 28589-28612.

Zhang, D., G. Shi, Y. Iwasaka, and M. Hu, 2000: Mixture of sulfate and nitrate in coastal atmospheric aerosols: individual particle studies in Qingdao $\left(36^{\circ} 04^{\prime} \mathrm{N}, 120^{\circ} 21^{\prime} \mathrm{E}\right)$. China Atmos. Environ., 34, 2669-2679.

Zhang, X. Y., S. L. Gong, Z. X. Shen, F. M. Mei, X. X. Xi, L. C. Liu, Z. J. Zhou, D. Wang, Y. Q. Wang, and Y. Cheng, 2003: Characterization of soil dust aerosol in China and its transport and distribution during 2001 ACE-Asia: 1. Network observations. J. Geophys. Res., 108, 4261, doi: 10.1029/2002JD002632.

Zhuang, G., Z. Yi, R. A. Duce, and P. R. Brown, 1992: Link between iron and sulfur suggested by the detection of Fe (II) in remote marine aerosols. Nature, 355, 537-539.

Zhuang, G. S., J. H. Guo, H. Yuan, and C. Y. Zhao, 2001: The compositions, sources, and size distribution of the dust storm from China in spring 2000 and its impact on the global environment. China Sci. Bull., 46, 895-901. 
Zou, Y., Z. Hong, L. Zhou, and J. Shen, 1991: The measuremental study of $\mathrm{SO}_{2}$ in Shanghai area. Sci. Atmos. Sinica, 15, 38-43.

Zhao, X., Z. Wang, G. Zhuang, and C. Pang, 2007: Model study on the transport and mixing of dust aerosols and pollutants during an Asian dust storm in March 2002. Terr. Atmos. Ocean. Sci., 18, 437-457, doi: 10.3319/TAO.2007.18.3.437(EA). 